Scholars International Journal of Chemistry and Material Sciences

Abbreviated Key Title: Sch Int J Chem Mater Sci

ISSN 2616-8669 (Print) |ISSN 2617-6556 (Online)

Scholars Middle East Publishers, Dubai, United Arab Emirates

Journal homepage: http://saudijournals.com/sijcms/

\title{
Impact of Insulation and Sheathing PVC Mixture on the Physical Properties
}

\author{
Abdel Hamid M. S. Esmail ${ }^{*}$ \\ Chemical Skills Department, Jubail Technical Institute, College and Institute Sector, Royal Commission for Jubail \& Yanbu, KSA
}

DOI: $10.36348 /$ sijems.2020.v03i03.002

| Received: 04.03.2020 | Accepted: 13.03.2020 | Published: 18.03.2020

*Corresponding author: Abdel Hamid M. S. Esmail

\section{Abstract}

The cable insulation and sheathing industry uses many different types of plastics depending on usage, application. Physical and electrical properties are one of the most important factors that compete and help to choose these materials when compared with other materials. These properties change with the change of the chemical components of the plastics mixture. The use of PVC material in the manufacture of cable wire coating has been used for decades. In this study, the effect of changing the proportions of the used components in the PVC mixture of the physical and electrical properties of cable wiring materials was investigated. Emphasis was placed on three properties: Tensile Strength and Loss of Mass and Insulation Resistance. In this study author discussed how to enhance these properties and improve them by working to raise the proportions of some of the substances in the PVC mixture while preserving other properties. The study aimed to prove the strong relationship between some components of PVC mixture used in cable insulation and sheathing industry and the physical and electrical properties of these products, and then focus on three components in the mixture and three properties. Random samples were taken and the mean percentages of the ingredients in the mixes were taken using various tools and several statistical methods such as correlation coefficient and regression analysis to prove the relationship between the ratios of some materials and the properties. After the analysis, the p-value was less than 0.05 , which reinforces the relationship between the ratio and the properties. Finally, the physical and electrical properties of PVC blends can be improved by changing component ratios to reach the optimized mixture for specific use and application, taking into account other competitive issues such as the final price of the product, environmental impact, and others issues.

Keywords: Tensile Strength, Loss of Mass, Insulation Resistance, PVC, Calcium, Stabilizer.

Copyright @ 2020: This is an open-access article distributed under the terms of the Creative Commons Attribution license which permits unrestricted use, distribution, and reproduction in any medium for non-commercial use (NonCommercial, or CC-BY-NC) provided the original author and source are credited.

\section{INTRODUCTION}

Engineering Technical Polyvinyl chloride (PVC) is one of the most important polymer materials in many different industries [6]. Also, because it provides more plastic and less bending radius for installation [2]. Also, it provides a strength and operating properties for cables as coated materials [5]. PVC used in the insulation and sheathing industry has many physical properties that qualify it to control a large part of the insulation and sheathing industry. It use in the inner layer or in the outer layer [4]. The uses of this industry vary in terms of products, diversified according to the British standard [8], which classified these products in terms of maximum operating temperature Between the two temperatures $\left(70-90^{\circ} \mathrm{C}\right)$, PVC is used as a basis for the mixture including calcium, which acts as a strengthen materials to improve the qualities and durability and increase tensile strength, and the stabilizer works to prevent thermal and chemical decomposition interact with free cracks and non-formation of HCL modules, also improves the creation of bonds for network configuration in the three dimensions, lubricants adds a soft texture to the plastic surface and prevents adhesion to the mold [3]. The PVC work with types of cables, whether copper and armored conductors of steel, aluminum or other [1].

The physical properties of the PVC used in the insulation and sheathing industry is an important part of the product excellence (quality) as well as the price. These properties include; Hardness Shore (A) - Specific Gravity $\left(\mathrm{gm} / \mathrm{cm}^{3}\right)$ - Elongation at Break (\%) - Tensile Strength $\left(\mathrm{N} / \mathrm{mm}^{2}\right)$ - Loss of Mass $\left(\mathrm{mg} / \mathrm{cm}^{2}\right)$ - Volume Resistivity $(\mathrm{Ohm} \mathrm{cm})$-Insulation Resistance (k-value $20^{\circ} \mathrm{C}$ ) - Insulation Resistance ( $\left.\mathrm{M} \Omega \mathrm{km} 70^{\circ} \mathrm{C}\right)$. Physical properties vary greatly depending on PVC components in the insulation and sheathing industry and by knowing 
the proportions of compounds involved in PVC mixture can make various products according to demand and also very special specifications [7]. Another process of working with PVC to affect the properties is the method for dosing a blowing agent into PVC by means of mixing was found effective. But no changes in the product appearance or properties were observed [6]. Moreover, some studies were conducted on Nanoadditives for Cable-Grade PVC and on the thermal stability and $\mathrm{HCl}$ evolution of P-PVC were deeply investigated by thermogravimetric analysis and reference ASTM methods. Also the hardness and mechanical properties were studied in order to highlight the effects of these additives in the perspective of final industrial uses [9]. The recent studies aim of studying the changes in the electro-physical properties of fireproof composite materials copolymer depending on the concentration of the modifier. Throughout investigate the electrical strength of polymer compositions and the specific volume electrical resistance of polymer compositions and the dielectric loss tangent and permittivity of polymer compositions [10]. Most of researcher examines the influence of the thermal conductivity characterizing the different materials surrounding the cable and how it provides a dimensionless coefficient to correct the International Electro-technical Commission (IEC) formula [11]. Some study goes for the insulation failure experiment of a cable exposed to heat and the relationship between failed time, equivalent thermal diffusion coefficient, and thickness of expansion layer which was determined. Resulting some difficulties in the thermal-physical parameter determination of fire-retardant coatings for cables, and method to determine the equivalent thermal diffusion coefficient of a fire-retardant coating was proposed combines both numerical and experimental means [12].

On the other hand, some studies focus on cable grade formulations based on P-PVC which can be improved for their performances, in particular concerning thermal stability and $\mathrm{HCl}$ release reduction [9]. PVC has significantly greater flame resistance than polyethylene, but other additives are required to make it flexible and stable. The plasticizers added to PVC are not, so additional flame retardants have to be added to PVC for use in some wiring applications [14]. Another study mentioned that although only limited value in high frequency work, it is of great value as an insulator, for direct current and low frequency alternating carriers. It has almost completely replaced rubber insulating wire for domestic flex and is widely used industrially. PVC sheathing is widely used in cable [15].

In this study were investigated the significant evidence to conclude that the amount of PVC Polymer affects the tensile strength, Calcium affects the loss of Mass, amount of Stabilizer affects the insulation resistance of the insulation and sheathing materials.
Some statistical methods such as the correlation coefficient, were used to determine the degree of correlation of material change in PVC mixture to the change of physical and electrical properties, and then moved to the Analysis of Variance (ANOVA) to study the hypotheses of the study and then to reach specific results. Relationship between material change in PVC mixture on physical and electrical properties.

\section{RESEARCH OBJECTIVES}

The objectives of the study are to enhance the physical and electrical properties of PVC insulation and sheathing products as a key component by changing the concentrations of chemicals involved in the chemical mixture of the product. The study also aims to reveal the form of the link between chemicals and physical and electrical properties of insulation and sheathing products and their change.

\section{MATERIALS AND METHODS}

The study was conducted in the national plastic company using the company's equipment to extract the results of the perform experiments. This was during the period of my work in the company to develop the operating conditions to produce materials with high competitive specifications to fulfill the market customers' needs.

The study was done to make PVC polymer blends according to the British specifications in general and the goal of the experiments were to obtain the highest possible physical and electrical properties at specific and semi-stable operating conditions, as the study did not address the detailed operating conditions and the method of manufacturing PVC used in insulation and sheathing. The results of the experiments are summarized in a table of average ratios of the mixtures and a table of the results of the technical tests of the physical and electrical properties of the products. Including hypothesis and charts.

A combination of seven PVC mixtures for seven products was used. In this study, I have focused on three physical and electrical properties to be studied based on the change in the composition of the input materials for each type of PVC mixture used in the industry. These properties are; Tensile Strength $\left(\mathrm{N} / \mathrm{mm}^{2}\right)$ - Loss of Mass $\left(\mathrm{mg} / \mathrm{cm}^{2}\right)$ - Insulation Resistance (k-value $20^{\circ} \mathrm{C}$ ).

\section{Correlation of change in the proportions of PVC mixtures on physical properties}

Distribution of chemical ratios for simulation of mixtures according to British standards. The results of the mixtures were summarized with their contents for each product to study its physical and electrical properties separately to determine the greatest effect of the materials in the mixture as in Table- 1 . 
Table-1: Percentage of the materials in the PVC mixture

\begin{tabular}{|c|c|c|c|c|c|}
\hline $\begin{array}{c}\text { Type of Mixture } \\
\text { (BS 6746) }\end{array}$ & $\begin{array}{c}\text { PVC } \\
\text { Polymer }\end{array}$ & Calcium & Stabilizer & Lubricant & $\begin{array}{c}\text { Plasticize } \\
\text { r }\end{array}$ \\
\hline TM 1 & $43 \%$ & $32 \%$ & $2 \%$ & $0.1 \%$ & $23 \%$ \\
\hline TM2 & $42 \%$ & $32 \%$ & $2 \%$ & $0 \%$ & $24 \%$ \\
\hline TYPE 4 & $42 \%$ & $31 \%$ & $1 \%$ & $0 \%$ & $25 \%$ \\
\hline TYPE 5 & $44 \%$ & $31 \%$ & $2 \%$ & $0.1 \%$ & $24 \%$ \\
\hline TI 1 & $44 \%$ & $27 \%$ & $2 \%$ & $0.1 \%$ & $27 \%$ \\
\hline TI 3 & $53 \%$ & $20 \%$ & $4 \%$ & $0 \%$ & $24 \%$ \\
\hline TYPE 6 & $60 \%$ & $15 \%$ & $3 \%$ & $0 \%$ & $22 \%$ \\
\hline TYPE 2 & $56 \%$ & $14 \%$ & $8 \%$ & $0 \%$ & $22 \%$ \\
\hline
\end{tabular}

TM 1 (for use over cables- Sheath, Max. $70^{\circ} \mathrm{C}$ ), TM2 (Flexible Insulation, Max. $70^{\circ} \mathrm{C}$ ), TYPE 4 (Flexible Insulation, Max. $85^{\circ} \mathrm{C}$ ), TYPE 5 (Hard Sheath, Max. $85^{\circ} \mathrm{C}$ ), TI 1 (Insulation for General Purpose, Max. $70^{\circ} \mathrm{C}$ ), TI 3 (Insulation for Heat Resistant, Max. $90^{\circ} \mathrm{C}$ ), TYPE 6 (Sheath for General Purpose, Max. $70^{\circ} \mathrm{C}$ ), TYPE 2 (Hard Insulation, Max. $\left.70^{\circ} \mathrm{C}\right)[8]$.

Then, the physical and electrical properties of each mixture were studied and analyzed. Eight properties were selected to determine the effect of chemical ratios on the physical and electrical properties and to know where the increase and decrease in the properties are happening according to the change in the ratios of the chemicals as it's appears in Table- 2 below.

A preliminary study was conducted to clarify the relationship between the ratios of the substances in the mixtures and the physical and electrical properties by using the correlation coefficient of the two sets of the data to determine the relationship between them as per the following equation:

$$
\begin{aligned}
& \operatorname{Correl}(X, Y)=\frac{\sum(x-\bar{x})(y-\bar{y})}{\sqrt{\sum(x-\bar{x})^{2} \sum(y-\bar{y})^{2}}} \\
& \text { Where } \quad \bar{x} \text { and } \bar{y}
\end{aligned}
$$

Are the Average (Percentage of the materials) and Average (Physical and Electrical properties).

The results are summarized in Table- 3 below. The relationship between some materials and their ratios and some physical and electrical properties are clearly and prominently appears and they discussed with details.

\begin{tabular}{|c|c|c|c|c|c|c|c|c|}
\hline $\begin{array}{l}\text { Type of Mix ture } \\
\text { (BS 6746) }\end{array}$ & 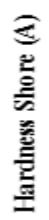 & 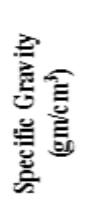 & 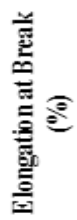 & 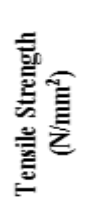 & 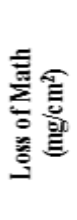 & 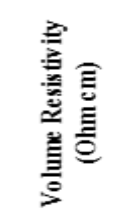 & 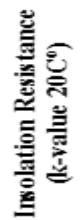 & 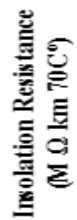 \\
\hline TM 1 & 90 & 1.53 & 350 & 14.5 & 1 & $1 \times 10^{12}$ & 74 & 0.8 \\
\hline TM2 & 90 & 1.52 & 330 & 14 & 1 & $2 \times 10^{11}$ & 83 & 0.7 \\
\hline TYPE 4 & 91 & 1.38 & 390 & 15.8 & 0.7 & $2 \times 10^{12}$ & - & 1.3 \\
\hline T YPE 5 & 86 & 1.51 & 300 & 15.5 & - & $5 \times 10^{11}$ & 182 & - \\
\hline TI 1 & 83 & 1.39 & 400 & 17 & 0.46 & $1.29 \times 10^{13}$ & 49.8 & - \\
\hline TI 3 & 89 & 1.45 & 390 & 21 & 0.29 & $1.4 \times 10^{15}$ & 730 & - \\
\hline T YPE 6 & 88 & 1.5 & 360 & 22 & 0.28 & $5 \times 10^{13}$ & 2000 & - \\
\hline TYPE 2 & 92 & 1.42 & 400 & 18.5 & 0.4 & $4.2 \times 10^{17}$ & 4400 & - \\
\hline
\end{tabular}

Table-2: Physical and Electrical properties of the PVC mixture

\begin{tabular}{|c|c|c|c|c|c|}
\hline Physical and Electrical Properties & PVC Polymer & Calcium & Stabilizer & Lubricant & Plasticizer \\
\hline Hard ness Shore (A) & $18.74 \%$ & $-16.40 \%$ & $40.94 \%$ & $32.73 \%$ & $-55.07 \%$ \\
\hline Specific Gravity (gm/ $\left./ \mathrm{cm}^{3}\right)$ & $-0.21 \%$ & $18.42 \%$ & $-19.64 \%$ & $-15.18 \%$ & $-60.70 \%$ \\
\hline Elongation at Break (\%) & $31.57 \%$ & $-47.03 \%$ & $40.94 \%$ & $45.96 \%$ & $31.00 \%$ \\
\hline Tensile Strength (N/mm²) & $90.40 \%$ & $-88.13 \%$ & $42.16 \%$ & $81.53 \%$ & $-35.92 \%$ \\
\hline Loss of Math $\left(\mathrm{mg} / \mathrm{cm}^{2}\right)$ & $-78.90 \%$ & $85.05 \%$ & $-46.95 \%$ & $-76.51 \%$ & $11.00 \%$ \\
\hline Volume Resistiv ity (Ohm cm) & $44.56 \%$ & $-58.87 \%$ & $94.27 \%$ & $63.04 \%$ & $-3521 \%$ \\
\hline Insulation Resistance ( $\mathrm{k}-\mathrm{r}$ alue $2 \mathrm{CC}^{\circ}$ ) & $76.39 \%$ & $-84.27 \%$ & $94.22 \%$ & $81.31 \%$ & $-55.10 \%$ \\
\hline Insulation Resistance $\left(\mathrm{M} \Omega \mathrm{km} 7 \mathrm{C}^{\circ}\right.$ ) & $-77.46 \%$ & $-84.46 \%$ & $-98.42 \%$ & $-77.46 \%$ & $89.65 \%$ \\
\hline
\end{tabular}




\section{Correlation of PVC ratios with Tensile Strength}

From the Table-3, the correlation coefficient between PVC ratio and tensile strength is $(90.4 \%)$, so regression analysis and ANOVA was used to test the study hypothesis.

Is there significant evidence to conclude that the amount of PVC Polymer affects the tensile strength of the insulation and sheathing materials?
The results appear in Table-4, the p-value is recorded as 0.002056219 . Since the p-value is small, we can reject the null hypothesis and conclude that there is evidence that PVC ratio affects the tensile strength test results.

Table-4: Regression analysis of PVC ratios with Tensile Strength

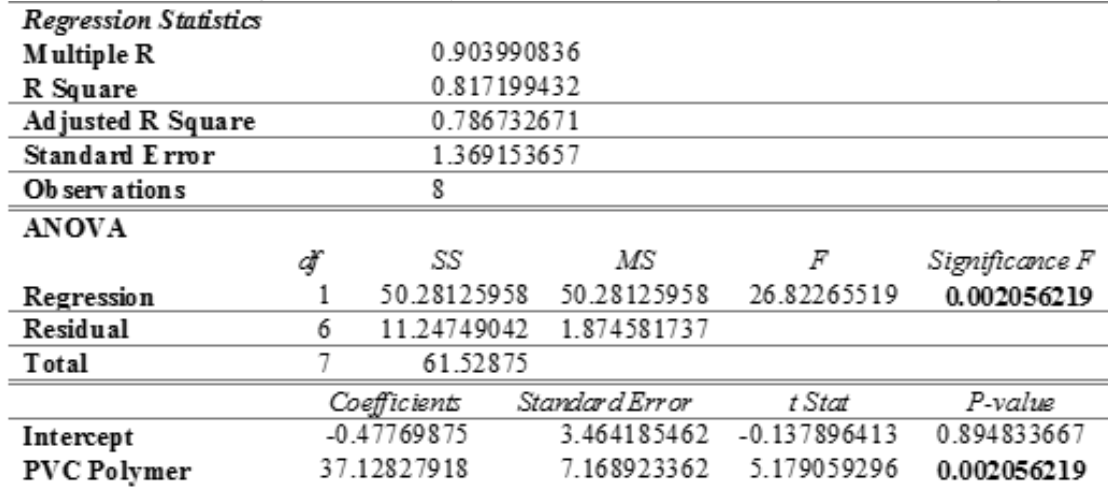

Table-5: Regression analysis of calcium ratios with Loss of Mass

\begin{tabular}{|c|c|c|c|c|}
\hline \multicolumn{5}{|l|}{ Regression Statistics } \\
\hline Multiple R & 0.85049424 & & & \\
\hline R Square & 0.72334045 & & & \\
\hline Adjusted R Square & 0.66800855 & & & \\
\hline Standard E rror & 0.18028300 & & & \\
\hline Observations & 7 & & & \\
\hline \multicolumn{5}{|l|}{ ANOVA } \\
\hline$d f$ & SS & $M S$ & $F$ & Significance $F$ \\
\hline Regression & 0.424890185 & 0.424890185 & 13.0727546 & 0.015289661 \\
\hline Residual & 0.162509815 & 0.032501963 & & \\
\hline \multirow[t]{2}{*}{ Total } & 0.5874 & & & \\
\hline & Coefficients & Standard Error & tStat & P-value \\
\hline Intercept & -0.219860273 & 0.234124273 & -0.939075093 & 0.39080588 \\
\hline Calcium & 3.313847851 & 0.916534908 & 3.615626446 & 0.01528966 \\
\hline
\end{tabular}

\section{Correlation of calcium ratios with Loss of Mass}

The correlation coefficient between calcium ratios with loss of Mass is (85.05\%), so regression analysis and ANOVA was used to test the study hypothesis.

Is there significant evidence to conclude that the amount of Calcium affects the loss of Mass of the insulation and sheathing materials?

The results appear in Table-5, the p-value is recorded as 0.015289661 . Since the p-value is small, we can reject the null hypothesis and conclude that there is evidence that calcium ratio affects the loss of Mass test results.

\section{Correlation of Stabilizer ratios with Insulation Resistance}

The correlation coefficient between stabilizer ratios with insulation resistance is $(94.22 \%)$, so regression analysis and ANOVA was used to test the study hypothesis.

Is there significant evidence to conclude that the amount of Stabilizer affects the insulation resistance of the insulation and sheathing materials?

The results appear in table 6 , the p-value is recorded as 0.001495815 . Since the p-value is small, we can reject the null hypothesis and conclude that there is evidence that stabilizer ratio affects the insulation resistance test results. 
Table-6: Regression analysis of Stabilizer ratios with Insulation Resistance

\begin{tabular}{|c|c|c|c|c|c|}
\hline \multicolumn{6}{|c|}{ Regression Statistics } \\
\hline \multicolumn{2}{|c|}{ Multiple R } & \multicolumn{2}{|c|}{0.942189945} & & \\
\hline \multicolumn{2}{|l|}{ R Square } & \multicolumn{2}{|c|}{0.887721893} & & \\
\hline \multirow{2}{*}{\multicolumn{2}{|c|}{$\begin{array}{l}\text { Adjusted R Square } \\
\text { Standard Error }\end{array}$}} & \multicolumn{2}{|c|}{0.865266272} & & \\
\hline & & \multicolumn{2}{|c|}{596.87047} & & \\
\hline \multicolumn{2}{|c|}{ Ob servations } & \multicolumn{2}{|c|}{7} & & \\
\hline \multicolumn{6}{|c|}{ ANOVA } \\
\hline & $d f$ & SS & MS & F & Significance $F$ \\
\hline Regression & 1 & 14083546.76 & 14083546.76 & 39.53227923 & 0.001495815 \\
\hline Resid ual & 5 & 1781271.79 & 356254.358 & & \\
\hline \multirow[t]{2}{*}{ Total } & 6 & 15864818.55 & & & \\
\hline & \multicolumn{2}{|c|}{ Coefficients } & Standard Error & $t$ Stat & $P$-value \\
\hline Intercept & \multicolumn{2}{|c|}{-1363.227387} & 448.5158699 & -3.039418398 & 0.028769885 \\
\hline Stabilizer & \multicolumn{2}{|c|}{73810.50422} & 11739.30118 & 6.287470019 & 0.001495815 \\
\hline
\end{tabular}

\section{RESULTS}

From the test results of physical and electrical properties it is clear that the tensile strength ranges between $\left(14 \mathrm{~N} / \mathrm{mm}^{2}\right)$ and $\left(22 \mathrm{~N} / \mathrm{mm}^{2}\right)$, and the ratio of PVC for all types in the mixes between (42\%) and $(60 \%)$. The loss of mass in the tested samples ranges from $\left(0.28 \mathrm{mg} / \mathrm{cm}^{2}\right)$ to $\left(1 \mathrm{mg} / \mathrm{cm}^{2}\right)$, corresponding to calcium ratios which is ranging from (14\%) to (32\%). The ratios of the stabilizer in the mixture samples range between (2\%) and (8\%) and caused insulation resistance between $\left(49.8 \mathrm{k}\right.$-value $\left.20^{\circ} \mathrm{C}\right)$ and $(4400 \mathrm{k}-$ value $20^{\circ} \mathrm{C}$ ).

Moving to track the change in the proportion of chemicals in the mixtures (PVC, calcium and stabilizer) with the change of physical and electrical properties .Graphs were made to illustrate this change and come up with a clear vision to work to improve these physical and electrical properties taking into account other factors that not addressed in this study.

\section{Direction of the impact of PVC change in Tensile Strength}

Figure-1 shows that the relationship between PVC and tensile strength is positive. Which means, of increasing the percentage of PVC in the mix from $(42 \%)$ to $(60 \%)$ the tensile strength increased from (14 $\left.\mathrm{N} / \mathrm{mm}^{2}\right)$ to $\left(22 \mathrm{~N} / \mathrm{mm}^{2}\right)$, depending on the type of product required and according to its use.

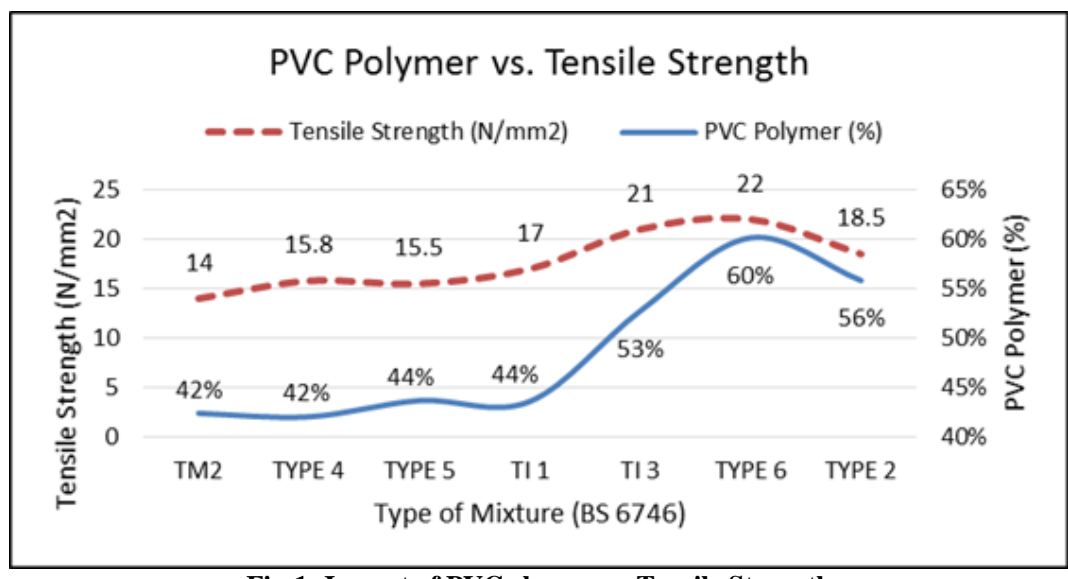

Fig-1: Impact of PVC change on Tensile Strength

\section{Direction of the impact of calcium change in Loss of Mass}

The relationship between calcium and loss of Mass is positive as it appears in Figure-2. Which means, of increasing the percentage of calcium in the mix from $(14 \%)$ to $(32 \%)$ the loss of Mass increased from $\left(0.28 \mathrm{mg} / \mathrm{cm}^{2}\right)$ to $\left(1 \mathrm{mg} / \mathrm{cm}^{2}\right)$, depending on the type of product required and according to its use. 


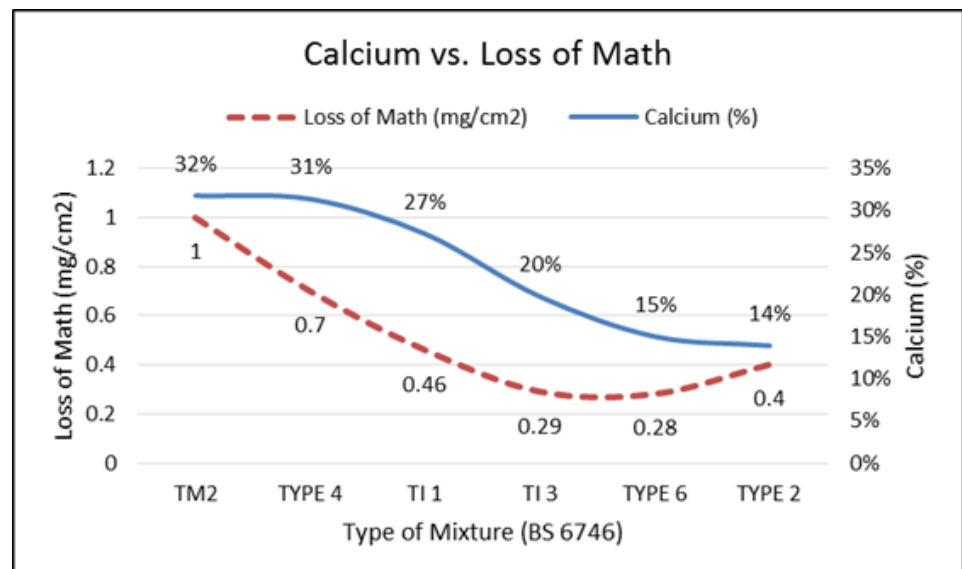

Fig-2: Impact of calcium change on loss of Mass

Direction of the impact of stabilizer change in insulation resistance

Figure-3 shows that the relationship between stabilizer and insulation resistance is positive. Which means, of increasing the percentage of stabilizer in the mix from $(2 \%)$ to $(8 \%)$ the insulation resistance increased from $\left(49.8 \mathrm{k}\right.$-value $\left.20^{\circ} \mathrm{C}\right)$ to $(4400 \mathrm{k}$-value $20^{\circ} \mathrm{C}$ ), depending on the type of product required and according to its use.

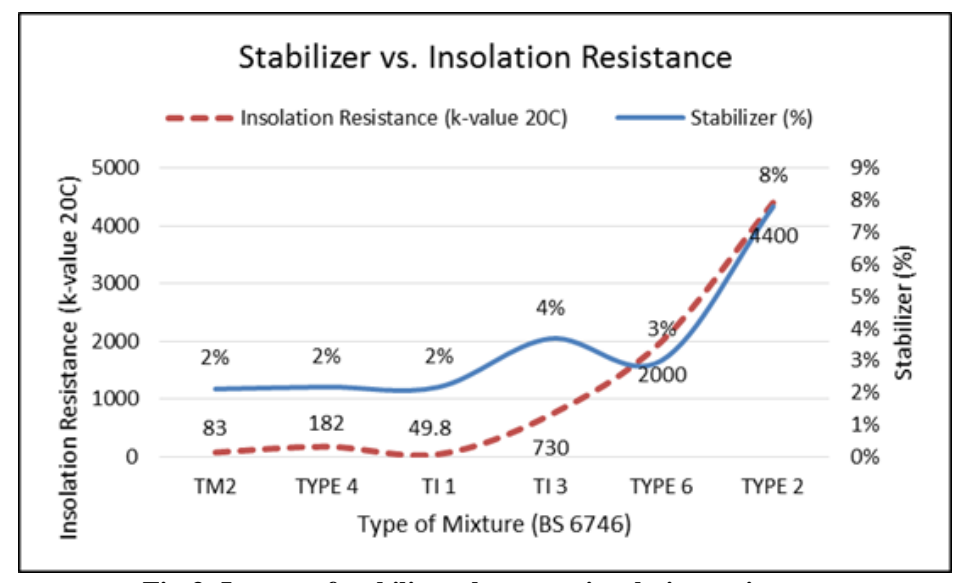

Fig-3: Impact of stabilizer change on insulation resistance

\section{DISCUSSION}

From the previous results, it is obvious that the proportions of the materials in the cables insulation and sheathing significantly affect the physical and electrical properties. It is also possible to work with other physical and electrical properties that did not address in the study in several other ways to detect the complex relationships that link the impact of changing ratios of materials on different properties.

\section{CONCLUSION}

From this study and other studies, it is clear that PVC is well-suited and the importance of enhancing its physical, electrical and other properties, due to the low cost of PVC used in the insulation and sheathing cable industry and its low impact on the environment in general. Taking into account that there are many different factors that can work individually or in combination did not address in this study. Some study worked previously on the mica-filled PVC composite which increases with an increase in filler loading irrespective of the particle size of the filler and its surface treatment as this is related to the dispersion, surface area, and particle size of mica. Tensile strength and elongation at break of composites go on reducing with higher loading of mica in all the composites [13].

\section{ACKNOWLEDGEMENTS}

Author thank Allah for health, and extend his sincere thanks to the national plastic company for their support and allow him to use the company's equipment and lab for scientific research projects.

\section{REFERENCES}

1. Tawancy, H. M., \& Hassan, M. (2016). On the degradation mechanism of low-voltage underground cable with poly (vinyl chloride) insulation. Journal of Materials Engineering and Performance, 25(6):2288-2295.

2. Babrauskas, V. (2006). Mechanisms and modes for ignition of low-voltage, PVC-insulated electrotechnical products. Fire and Materials, 30(2):151-174, 
3. Grossman, R. F. (2008). Handbook of Vinyl Formulating, Wiley Series on Plastics Engineering \& Technology. Edition: 2nd ed. Hoboken: WileyInterscience. eBook.

4. Wilkes, C. E., Summers, J. W., Daniels, C. A., \& Berard, M. T. (2005). PVC handbook, Wilkes, C. E., Daniels, C. A., Summers, J. W., Hanser, J. W. Ed., Publications, Cincinnati, 173-335

5. Klempner, D., Sendijarevic, V., \& Aseeva, R. M. (2004). Polymeric foams and foam technology. 2004.

6. Garbacz, T. (2014). Properties and Physical Structure of Cellular PVC Coatings. Cellular Polymers, 33(2):87-106.

7. Simonik, J. (2000). Properties and Physical Structure of Cellular PVC Coatings. The Polymer Processing Society, Sixteenth Annual Meeting, Shanghai, China, 276.

8. [8] British Standard, Specification for insulation and sheathing for electric cables, (1990), (BS 6746:1990).

9. Palin, L., Rombolà, G., Milanesio, M., \& Boccaleri, E. (2019). The Use of POSS-Based Nanoadditives for Cable-Grade PVC: Effects on Its Thermal Stability. Polymers, 11(7), 1105.
10. Chulieieva, O. (2019). Investigation of electrophysical properties of nanomodified fireproof eva polymer compositions. Technology audit and production reserves, $1(1$ (45)), 31-38.

11. Salata, F., Nardecchia, F., Gugliermetti, F., \& de Lieto Vollaro, A. (2016). How thermal conductivity of excavation materials affects the behavior of underground power cables. Applied Thermal Engineering, 100:528-537

12. Shu, Z. J., Wang, J., \& Zhou, L. (2014). Method to determine the equivalent thermal diffusion coefficient of the intumescent coating for cables. Journal of Coatings Technology and Research, 11(5), 817-826.

13. Deshmukh, S. P., Rao, A. C., Gaval, V. R., \& Mahanwar, P. A. (2011). Mica-filled PVC composites: effect of particle size, filler concentration, and surface treatment of the filler, on mechanical and electrical properties of the composites. Journal of Thermoplastic Composite Materials, 24(5), 583-599.

14. Wilson, A. (2009). Getting down to the wire. Architectural Record, 12(4):4.

15. Soundararajan, S. (2015). Thermoplastic \& thermoset plastic insulating materials. Popular Plastics \& Packaging, 60(11):21-25. 